\title{
Synthesis and Characterization of a Tripodal Tris(nitroxide) Aluminum Complex and Its Catalytic Activity toward Carbonyl Hydroboration
}

\author{
Audra J. Woodside, ${ }^{\dagger}$ Mackinsey A. Smith, ${ }^{\dagger}$ Thomas M. Herb, ${ }^{\ddagger}$ Brian C. Manor, ${ }^{\S}$ Patrick J. Carroll, ${ }^{\S}$
} Paul R. Rablen, ${ }^{\dagger}$ a and Christopher R. Graves* ${ }^{* \dagger}$

${ }^{\dagger}$ Department of Chemistry \& Biochemistry, Swarthmore College, 500 College Avenue, Swarthmore, Pennsylvania 19081, United States

${ }^{\ddagger}$ Department of Chemistry \& Biochemistry, Albright College, 13th and Bern Streets, Reading, Pennsylvania 19612, United States

${ }^{\S}$ Department of Chemistry, University of Pennsylvania, 231 South 34th Street, Philadelphia, Pennsylvania 19104, United States

Supporting Information

ABSTRACT: An aluminum complex of a tripodal tris(nitroxide)-based ligand has been prepared and characterized. The complex has the ability to participate in metal-ligand cooperative catalysis, which has been exploited for the hydroboration of both aldehydes and ketones. This represents new, transition-metal-like reactivity for an earth-abundant metal.

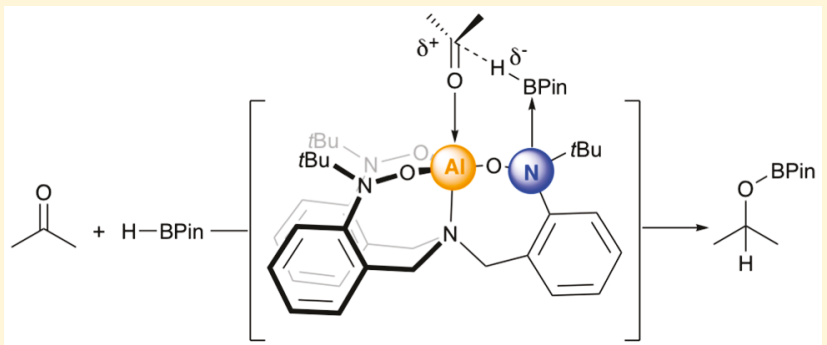

Metal-Ligand Cooperative Catalysis
$\mathrm{T}$ he development of catalyst systems implementing readily available resources is an important effort toward more sustainable synthetic practices. ${ }^{1}$ Aluminum is highly abundant in the earth's crust, ${ }^{2}$ making it an inexpensive and attractive choice for catalyst development. However, the lack of readily available redox chemistry has limited the applicability of conventional aluminum complexes in catalytic oxidative and reductive chemistries of organic molecules. In recent years, aluminum complexes of redox-active and/or noninnocent ligands have offered a platform through which to expand the utility of aluminum complexes in catalysis by moving away from traditional solely Lewis acid activation. ${ }^{3}$

Our efforts in this area have focused on the preparation of aluminum coordination complexes implementing ligands containing nitroxide functional groups. ${ }^{4,5}$ We have previously prepared complexes of the pyridyl hydroxyl amines $\left({ }^{\mathrm{R}} \mathrm{pyNO}^{-}\right)_{2} \mathrm{AlCl}\left({ }^{\mathrm{R}} \mathrm{pyNO}^{-}=\mathrm{N}\right.$-tert-butyl-N-(2-(5-R-pyridyl))nitroxyl, $\left.\mathrm{R}=\mathrm{H}, \mathrm{CH}_{3}, \mathrm{CF}_{3}\right)$ and explored their electrochemical behavior. However, in those systems the aluminum is coordinatively saturated and relatively unreactive. Herein we report the preparation of the aluminum complex of the tripodal tris(nitroxide) ligand $\left[\left\{\left(2-{ }^{t} \mathrm{BuNO}\right) \mathrm{C}_{6} \mathrm{H}_{4} \mathrm{CH}_{2}\right\}_{3} \mathrm{~N}\right]^{3-}$ (Tri$\left.\mathrm{NOx}^{3-}\right)^{6}$ and deduce its electronic structure. We also demonstrate the catalytic activity of the ( $\left.\mathrm{TriNOx}^{3-}\right) \mathrm{Al}$ complex toward the hydroboration of aldehydes and ketones and propose a mechanism that operates through metal-ligand cooperative bifunctional catalysis.

The reaction between $\mathrm{TriNOxH}_{3}$ and $\mathrm{AlMe}_{3}$ at room temperature results in deprotonation of two of the hydroxyl amines commensurate with transfer of the third $\mathrm{OH}$ proton to the bridgehead nitrogen of the ligand to give the zwitterion (HTriNOx)AlMe (1) (Scheme 1). Both the Al- $\mathrm{CH}_{3}(\delta-0.06$ $\mathrm{ppm})$ and $\mathrm{N}-\mathrm{H}(\delta \quad 11.14 \mathrm{ppm})$ functional groups are assignable in the ${ }^{1} \mathrm{H}$ NMR spectrum of 1 . The formation of $\mathbf{1}$ is similar to that of the $\left[\mathrm{O}_{3} \mathrm{PH}\right] \mathrm{AlCl}\left(\left[\mathrm{O}_{3} \mathrm{PH}\right]^{2-}=[(2-\mathrm{O}-3,5-\right.$ $\left.\left.t \mathrm{Bu}_{2} \mathrm{C}_{6} \mathrm{H}_{2}\right)_{3} \mathrm{PH}\right]^{2-}$ ) complex prepared by $\mathrm{Su}$ and Liang in the reaction between $\mathrm{AlCl}_{3}$ with $\left[\left(2-\mathrm{HO}-3,5-t \mathrm{Bu}_{2} \mathrm{C}_{6} \mathrm{H}_{2}\right)_{3} \mathrm{P}\right]^{7}$ and represents a rare example of a dianionic scorpionate ligand. $\mathrm{On}$ heating a sample of 1 at $100{ }^{\circ} \mathrm{C}$, the third deprotonation occurs to give the desired ( $\mathrm{TriNOx}^{3-}$ )Al complex (2), as evidenced by ${ }^{1} \mathrm{H}$ NMR spectroscopy. The (TriNOx)Al complex 2 was also prepared through deprotonation of the ligand precursor with 3 equiv of $\mathrm{NaN}\left(\mathrm{SiMe}_{3}\right)_{2}$ followed by salt metathesis with $\mathrm{AlCl}_{3}$. The complex is most conveniently isolated as the pyridine adduct ( $\mathrm{TriNOx}^{3-}$ )Al-py (2-py), which was prepared in $79 \%$ yield via the salt metathesis route.

The complex 2-py was readily characterized by ${ }^{1} \mathrm{H}$ and ${ }^{13} \mathrm{C}$ NMR spectroscopy. The complex exhibits one singlet resonance in the ${ }^{1} \mathrm{H}$ NMR spectra assignable to the $t \mathrm{Bu}$ groups, indicating 3-fold symmetry of the tripodal ligand when it is bound to the metal ion. The protons of the bridgehead $\mathrm{CH}_{2}$ groups are diasteriotopic, resulting in two doublets $(J \approx$ $11 \mathrm{~Hz}$ ) in the ${ }^{1} \mathrm{H} \mathrm{NMR}$, both of which integrate to three protons. The ${ }^{13} \mathrm{C}$ NMR spectra has six unique aromatic

Received: December 21, 2018

Published: February 18, 2019 
Scheme 1. Synthesis of the Complex (TriNOx ${ }^{3-}$ )Al-py (2py) through Deprotonation and Salt Metathesis and Its Reactivity with MeOTf

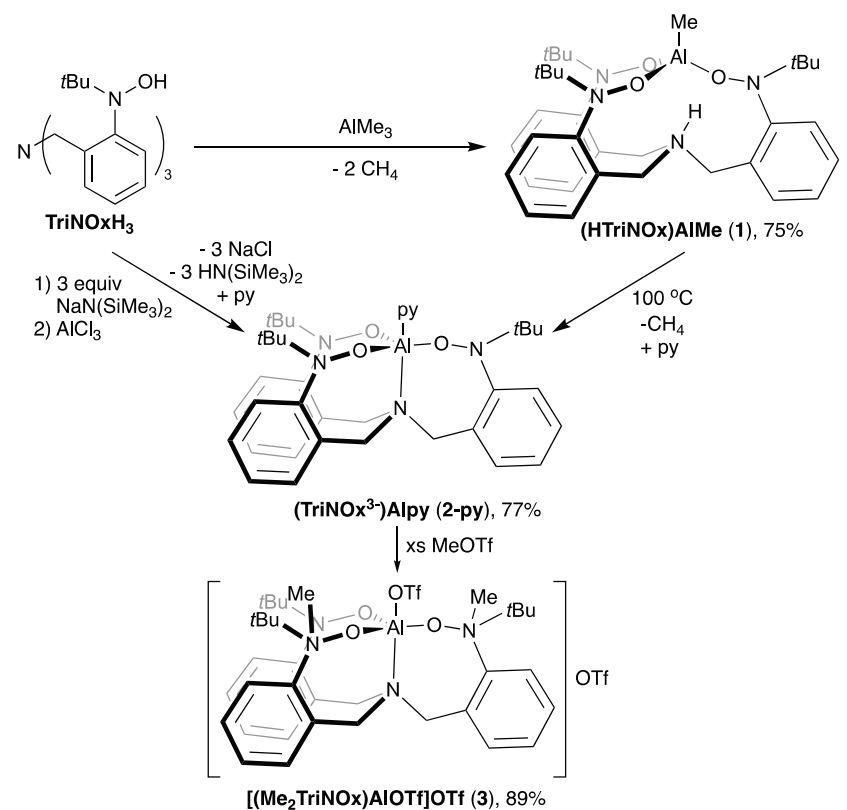

resonances assignable to the $\mathrm{TriNOx}^{3-}$ ligand along with signatures for both the $t \mathrm{Bu}$ substituents and methylene carbons. Single crystals of the (TriNOx ${ }^{3-}$ )Al-py complex were grown from a concentrated pyridine solution at $-5{ }^{\circ} \mathrm{C}$, allowing for X-ray crystallography to corroborate the formulation of 2-py. The molecule crystallizes in the centric space group $C 2 / c$. The asymmetric unit is disordered by having both enantiomers superimposed in unequal proportions. Figure 1 shows a representation of the major disorder

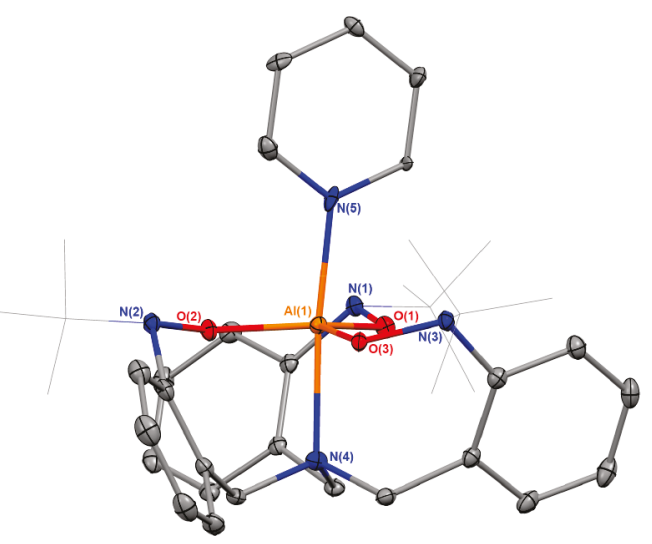

Figure 1. Solid-state structure of the complex $\left(\mathrm{TriNOx}^{3-}\right) \mathrm{Al}-\mathrm{py}(\mathbf{2 -}$ py). Ellipsoids are projected at the $50 \%$ probability level, and $\mathrm{H}$ atoms are omitted for clarity. tert-Butyl groups are depicted using a wireframe model.

component, and details of the refinement are given in the Supporting Information. The aluminum ion is pentacoordinate with a distorted-trigonal-bipyramidal geometry $\left(\tau_{5}=0.88\right){ }^{8}$ The average $\mathrm{N}-\mathrm{O}$ distance in 2-py is $1.44 \AA$, which compares well with analogous parameters for the series of rare-earth $\left(\mathrm{TriNOx}^{3-}\right) \mathrm{RE}$ complexes prepared by the Schelter group $\left(\mathrm{N}-\mathrm{O}_{\mathrm{ave}}=1.44 \AA\right)^{6,9,10}$ and suggests a fully reduced TriNO ${ }^{3-}$ ligand.
The geometry of the complex $\left(\mathrm{TriNO}^{3-}\right) \mathrm{Al}$-py was optimized using density functional theory. Overall the computed structure is in good agreement with the solid-state structure, with the bond distances centered around the aluminum ion being within $\sim 0.05 \AA$ (Table S4). Similarly, all of the bond angles are also in good agreement, with none of the angles deviating by more than $5^{\circ}$. The HOMO $(-4.522$ $\mathrm{eV})$, HOMO-1 $(-4.626 \mathrm{eV})$, and HOMO-2 $(-4.766 \mathrm{eV})$ are totally ligand based, with electron density primarily localized on the N-O arms.

The complex ( TriNOx $^{3-}$ )Al-py has the potential to exist over multiple redox states owing to the three nitroxide groups of the ligand. The cyclic voltammogram of 2-py was collected (Figure S11) and shown to exhibit two reversible features, which we assign to the sequential one-electron oxidation processes of the ligand to form the $\left[\left(\mathrm{TriNOx}^{2-}\right) \mathrm{Al}\right]^{+}$and $\left[\left(\mathrm{TriNOx}^{-}\right) \mathrm{Al}\right]^{2+}$ species. Optimization of the singly $\left([(\text { TriNOx }) A l]^{+}\right)$and doubly reduced $\left(\left[(\right.\right.$TriNOx $\left.) \mathrm{Al}^{2+}\right)$ compounds and visualization of their frontier orbitals support these assignments (see the Supporting Information): The SOMO of the $[(\text { TriNOx }) A l]^{+}$complex is ligand-based and primarily localized on one $\mathrm{N}-\mathrm{O}$ group and the attached aromatic ring. The LUMO of the $[(\text { TriNOx }) A l]^{2+}$ complex is also ligand-based, with the hole being delocalized over all three of the $\mathrm{ArN}-\mathrm{O}$ moieties.

The (TriNOx ${ }^{3-}$ )Al-py complex is able to act as both a Lewis acid through the aluminum ion and as a Lewis base through the nitrogen atoms of the nitroxide arms. For example, reaction of 2-py with excess methyl triflate results in $\mathrm{N}$-methylation of two of the $\mathrm{N}-\mathrm{O}$ arms of the ligand along with coordination of one triflate anion to the aluminum ion. Increasing the amount of MeOTf does not result in methylation of the third nitroxide nitrogen. The $\left[\left(\mathrm{Me}_{2}\right.\right.$ TriNOx $)$ AlOTf $]$ OTf product 3 was isolated in $89 \%$ yield (Scheme 1). The ${ }^{1} \mathrm{H}$ NMR spectra of 3 shows three unique $t \mathrm{Bu}$ resonances and six unique resonances assignable to the $\mathrm{C}-\mathrm{Hs}$ of the bridgehead methylene units, indicating desymmetrization of the ligand. There is only one signal in the ${ }^{19} \mathrm{~F}\left\{{ }^{1} \mathrm{H}\right\}$ NMR spectrum $(\delta$ $-79.35 \mathrm{ppm}$ ), suggesting rapid exchange of the inner- and outer-sphere triflate anions in solution. The dual Lewis basic/ Lewis acidic nature of the $\left(\mathrm{TriNO}^{3-}\right) \mathrm{Al}$ complex opens the possibility for metal-ligand cooperative bifunctional catalysis. With this in mind, we investigated the hydroboration of ketones with pinacolborane (HBPin) catalyzed by the (TriNOx)Al complex. With $10 \mathrm{~mol} \%$ loading of 2-py and 1.2 equiv of HBPin, the reduction of acetophenone was accomplished in 54\% yield at room temperature after $20 \mathrm{~h}$, in comparison to no product without the catalyst. Increasing the reaction temperature to $75{ }^{\circ} \mathrm{C}$ resulted in $70 \%$ product under otherwise identical reaction conditions. The activity of the catalyst was significantly improved by removal of the pyridine: use of $10 \mathrm{~mol} \%$ of the free-base complex 2 and 1.2 equiv of HBPin gave the borate ester $\mathbf{i}$ in quantitative yield after $20 \mathrm{~h}$ at room temperature (Scheme 2). These optimized conditions were applicable to a broader scope of ketones. Interestingly, incorporation of either electron-withdrawing or electrondonating groups significantly reduced the yield of borate ester product (ii and iii). The reduction of benzophenone was more difficult, with the reduced product iv being generated in only $18 \%$ yield. Increasing the reaction temperature to $75{ }^{\circ} \mathrm{C}$ did give product iv in 53\% yield. The reduction of 4-phenyl-3buten-2-one proceeded cleanly to give $\mathbf{v}$ in $60 \%$ yield. In this case, heating the sample to $75^{\circ} \mathrm{C}$ resulted in a reduced yield of 
Scheme 2. Scope of Hydroboration of Ketone Substrates ${ }^{a}$

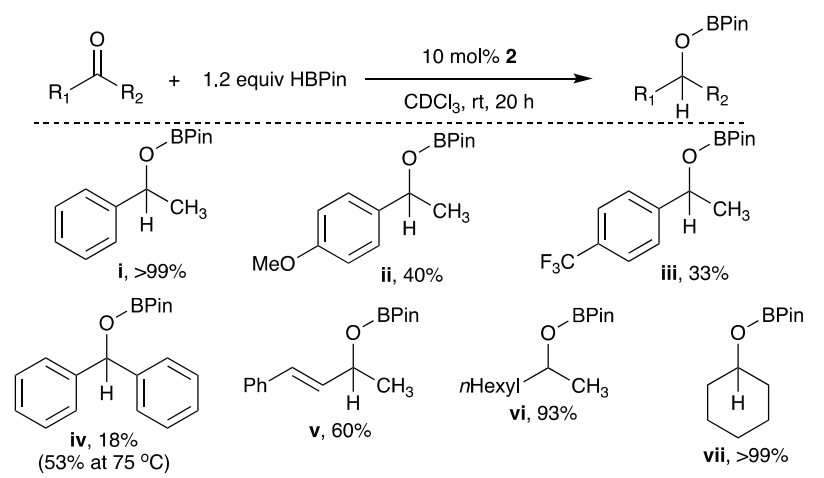

${ }^{a}$ Reaction conditions: ketone ( $\left.0.5 \mathrm{mmol}\right)$, HBPin $(0.6 \mathrm{mmol}), 2$ $(0.05 \mathrm{mmol}), \mathrm{CDCl}_{3}(1.0 \mathrm{~mL})$. Yields were determined by ${ }^{1} \mathrm{H}$ NMR spectroscopy using hexamethylcyclotrisiloxane $(0.083 \mathrm{mmol})$ as an internal standard.

product, which we hypothesize results from competitive reactivity with the alkene under the reaction conditions. The reduction of aliphatic ketones was also successful, with both 2octanone and cyclohexanone being reduced to their borate esters vi and vii, respectively, in excellent yields. Our hydroboration protocol could also be applied to aldehydes. As expected, aldehyde substrates are more easily reduced relative to their ketone counterparts and excellent yields of borate esters could be obtained using only 5 mol\% loading of 2 in only $4 \mathrm{~h}$ at room temperature (Scheme 3 ). Using these

Scheme 3. Scope of Hydroboration of Aldehyde Substrates ${ }^{a}$

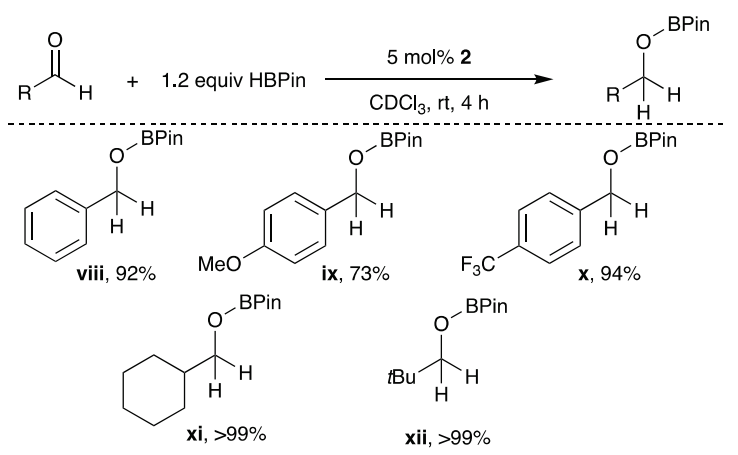

${ }^{a}$ Reaction conditions: aldehyde (0.5 mmol), HBPin (0.6 mmol), 2 (0.025 mmol), $\mathrm{CDCl}_{3}(1.0 \mathrm{~mL})$. Yields were determined by ${ }^{1} \mathrm{H}$ NMR spectroscopy using hexamethylcyclotrisiloxane $(0.083 \mathrm{mmol})$ as an internal standard.

conditions, benzaldehyde was reduced to boronate ester viii in $92 \%$ yield. In contrast to the ketone system, both electrondonating (ix) and -withdrawing ( $\mathbf{x})$ substituents were tolerated without a significant decrease in yield. Aliphatic aldehydes were also readily reduced (xi and xii).

The application of aluminum complexes as catalysts for the reduction of organic substrates has gained traction in recent years, ${ }^{11}$ including systems for the hydroboration of carbonyls. $^{12,13}$ In comparison to those systems, our catalyst is less active and higher catalyst loadings are required to obtain similar yields. We attribute this at least partially to a different mechanism for our catalyst. The previous systems implement complexes that have an $\mathrm{Al}-\mathrm{H}$ moiety which is proposed to insert into the carbonyl in a key mechanistic step. Our
( $\mathrm{TriNOx}^{3-}$ )Al system does not have an $\mathrm{Al}-\mathrm{H}$, and we propose an alternative mechanism that involves metal-ligand cooperative bifunctional catalysis (Scheme $\mathrm{S} 1$ ). The aluminum ion in ( TriNOx ${ }^{3-}$ )Al is Lewis acidic, as gauged by its measured AN value of $75,{ }^{14-16}$ which suggests interaction with and activation of the carbonyl substrate. This is supported by the observation that pyridine inhibits the reaction, presumably through competitive binding with the substrate at aluminum. Simultaneously, the borane can coordinate to one of the nitroxide nitrogens of the ligand, creating an adduct that polarizes the $\mathrm{B}-\mathrm{H}$ bond and increases its hydricity. Similar activation was reported in the $\mathrm{NaOH}$-catalyzed hydroboration system developed by Wu et al. ${ }^{17}$ This is also supported by the ${ }^{11} \mathrm{~B}$ NMR spectra of a mixture of HBPin and (TriNOx ${ }^{3-}$ )Al, which shows a slight upfield shift relative to free HBPin. Together, these dual activations result in delivery of the hydride to the carbonyl with installation of the $\mathrm{B}-\mathrm{O}$ bond to turn over the catalyst. The reaction between acetophenone and HBPin catalyzed by $\mathrm{AlCl}_{3}$ or $\mathrm{TriNOxH}_{3}$ gives product in only $12 \%$ and $9 \%$ yields, respectively, suggesting that both activation parameters are necessary for productive catalysis.

In conclusion, we have prepared an aluminum complex implementing a multidentate ligand incorporating multiple nitroxide functional groups. In addition to allowing for multiple redox states for the complex, the $\mathrm{N}-\mathrm{O}$ groups also add Lewis basic sites that can be coupled with the Lewis acidic aluminum ion to enable new activation parameters that result in transition-metal-like catalysis. This chemistry around an earth-abundant metal makes for an economically attractive lead for future research. We are currently investigating other reduction chemistries for which the ( $\mathrm{TriNOx}^{3-}$ )Al complex is catalytically viable and also deducing how changes in the ligand framework are manifested in changes in reactivity of the complex.

\section{ASSOCIATED CONTENT}

\section{S Supporting Information}

The Supporting Information is available free of charge on the ACS Publications website at DOI: 10.1021/acs.organomet.8b00933.

Experimental, crystallographic, and computational details, NMR spectra, visualization of molecular orbitals, and proposed catalytic cycle for the hydroboration reaction $(\mathrm{PDF})$

Cartesian coordinates for DFT-optimized structures (MOL)

\section{Accession Codes}

CCDC 1862705-1862707 contain the supplementary crystallographic data for this paper. These data can be obtained free of charge via www.ccdc.cam.ac.uk/data_request/cif, or by emailing data_request@ccdc.cam.ac.uk, or by contacting The Cambridge Crystallographic Data Centre, 12 Union Road, Cambridge CB2 1EZ, UK; fax: +44 1223336033.

\section{AUTHOR INFORMATION}

\section{Corresponding Author}

*E-mail for C.R.G.: cgraves1@swarthmore.edu.

ORCID ${ }^{\circ}$

Paul R. Rablen: 0000-0002-1300-1999

Christopher R. Graves: 0000-0001-5853-2446 


\section{Notes}

The authors declare no competing financial interest.

\section{ACKNOWLEDGMENTS}

C.R.G. thanks Swarthmore College and the National Science Foundation (CHE-1664902) for financial support of this work. A.J.W. was supported through a James H. Scheuer Summer Internship in Environmental Studies. M.A.S. was supported through a Frances Velay Women's Science Research Fellowship. We thank the NSF (CHE-1337494) for funding toward the NMR spectrometer used in this work. We thank Bren E. Cole (University of Pennsylvania) for assistance in collecting the X-ray diffraction data.

\section{REFERENCES}

(1) Catalysis without precious metals; Bullock, R. M., Ed.; WileyBlackwell: 2010; 290 pp.

(2) Rabinovich, D. The allure of aluminum. Nat. Chem. 2013, 5, 76.

(3) Berben, L. A. Catalysis by aluminum(III) complexes of noninnocent ligands. Chem. - Eur. J. 2015, 21, 2734-2742.

(4) Poitras, A. M.; Bogart, J. A.; Cole, B. E.; Carroll, P. J.; Schelter, E. J.; Graves, C. R. Synthesis and characterization of aluminum complexes of redox-active pyridyl nitroxide ligands. Inorg. Chem. 2015, 54, 10901-10908.

(5) Herb, T. M.; Poitras, A. M.; Richardson, K. G.; Cole, B. E.; Bogart, J. A.; Carroll, P. J.; Schelter, E. J.; Graves, C. R. Synthesis and characterization of aluminum nitroxide complexes. Polyhedron 2016, 114, 194-199.

(6) Bogart, J. A.; Lippincott, C. A.; Carroll, P. J.; Schelter, E. J. An operationally simple method for separating the rare-earth elements neodymium and dysprosium. Angew. Chem., Int. Ed. 2015, 54, 82228225.

(7) Su, W.-J.; Liang, L.-C. Elusive scorpionates: C3-Symmetric, formally dianionic, facially tridentate ligands. Inorg. Chem. 2018, 57, $553-556$.

(8) Addison, A. W.; Rao, T. N.; Reedijk, J.; Van Rijn, J.; Verschoor, G. C. Synthesis, structure, and spectroscopic properties of copper(II) compounds containing nitrogen-sulfur donor ligands: the crystal and molecular structure of aqua[1,7-bis(N-methylbenzimidazol-2'-yl)-2,6dithiaheptane]copper(II) perchlorate. J. Chem. Soc., Dalton Trans. 1984, 1349-1356.

(9) Bogart, J. A.; Lippincott, C. A.; Carroll, P. J.; Booth, C. H.; Schelter, E. J. Controlled redox chemistry at cerium within a tripodal nitroxide ligand framework. Chem. - Eur. J. 2015, 21, 17850-17859. (10) Bogart, J. A.; Cole, B. E.; Boreen, M. A.; Lippincott, C. A.; Manor, B. C.; Carroll, P. J.; Schelter, E. J. Accomplishing simple, solubility-based separations of rare earth elements with complexes bearing size-sensitive molecular apertures. Proc. Natl. Acad. Sci. U. S. A. 2016, 113, 14887-14892.

(11) Nikonov, G. I. New tricks for an old dog: Aluminum compounds as catalysts in reduction chemistry. ACS Catal. 2017, 7, $7257-7266$

(12) Jakhar, V. K.; Barman, M. K.; Nembenna, S. Aluminum monohydride catalyzed selective hydroboration of carbonyl compounds. Org. Lett. 2016, 18, 4710-4713.

(13) Yang, Z.; Zhong, M.; Ma, X.; De, S.; Anusha, C.; Parameswaran, P.; Roesky, H. W. An aluminum hydride that functions like a transition-metal catalyst. Angew. Chem., Int. Ed. 2015, 54, 10225-10229.

(14) Gutmann, V. Solvent effects on the reactivities of organometallic compounds. Coord. Chem. Rev. 1976, 18, 225-255.

(15) Beckett, M. A.; Strickland, G. C.; Holland, J. R.; Varma, K. S. A convenient NMR method for the measurement of Lewis acidity at boron centers: correlation of reaction rates of Lewis acid initiated epoxide polymerizations with Lewis acidity. Polymer 1996, 37, 46294631.
(16) The acceptor number (AN) was calculated by the GutmannBeckett method using the formula $\mathrm{AN}=2.21 \times\left(31 \mathrm{LA} \cdot \mathrm{Et}_{3} \mathrm{PO}-41\right)$. (17) Wu, Y.; Shan, C.; Ying, J.; Su, J.; Zhu, J.; Liu, L. L.; Zhao, Y. Catalytic hydroboration of aldehydes, ketones, alkynes and alkenes initiated by $\mathrm{NaOH}$. Green Chem. 2017, 19, 4169-4175. 